\title{
KARAKTERISTIK ALAT TANGKAP JARING INSANG (GILL NET) DI PANGKALAN PENDARATAN IKAN (PPI) MUARA ANGKE JAKARTA UTARA
}

\author{
Muhammad Natsir Kholis ${ }^{1 *}$ Made Mahendra Jaya ${ }^{2}$ Roma Yuli Hutapea ${ }^{2}$ Tri Nanda \\ Citra Bangun ${ }^{3}$ Kedswin Gerson Hehanussa ${ }^{3}$ \\ ${ }^{1}$ Staf Pengajar Jurusan Pemanfaatan Sumber daya Perikanan Fakultas Perikanan, \\ Universitas Muara Bungo Jambi \\ ${ }^{2}$ Staf Pengajar Jurusan Perikanan Tangkap, Politeknik KP Jembrana \\ ${ }^{2}$ Staf Pengajar Jurusan Perikanan Tangkap Politeknik KP Dumai \\ ${ }^{3}$ Alumni Pascasarjana Institut Pertanian Bogor \\ *Email: kholis2336@gmail.com
}

\begin{abstract}
ABSTRAK
Karakteristi $\mathrm{k}$ alat tangkap sangat penting untuk pengelolaan dan pengembangan perikanan tangkap yang berkelanjutan, dengan mengamati kontruksi, manajemen operasi penangkapan dan keramah lingkungan dari alat tangkap yang digunakan nelayan.Salah satu alat tangkap yang ada di PPI Muara Angke yaitu jaring insang (gill net).Penelitian ini bertujuan untuk mengidentifikasi karakteristik alat tangkap jaring insang (gill net) dan menguji tingkat keramah lingkungan alat tangkap jaring insang (gill net). Metode analisis yang digunakan yaitu deskriptif. Hasil penelitian menunjukkan bahwa karakteristik alat tangkap jaring insang (gill net) di PPI Muara Angke yaitu: webbing memiliki mesh size 2 inci, webbing menggunakan pelampung mini purse seine, tidak memiliki ikan target tangkapan yang spesifik, nelayan gill net rata-rata telah mencapai usia produktif dalam bekerja, kapal yang digunakan berkisar 830 GTdan kualitas hasil tangkapan rata-rata dalam kondisi segar. Hasil analisis alat tangkap ramah lingkungan gill net di PPI MuaraAngke dapat dikategorikan alat tangkap yang ramah lingkungan dengan skor 30,5.
\end{abstract}

KataKunci: Karakteristik, Gill net, Ramah lingkungan, MuaraAngke

\section{PENDAHULUAN}

\section{LatarBelakang}

Pelabuhan Muara Angke merupakan salah satu dari pelabuhan perikanan yang difungsikan sebagai tempat pendaratan ikan di wilayah bagian utara Jakarta. Pelabuhan ini termasuk dalam klasifikasi KKP tipe pelabuhan kelas D atau PPI.Awal mulanya pelabuhan perikanan Muara Angke sebagai tempat pendaratan ikan dan pelelangan ikan yang aktifitasnya sama dengan pelabuhan lainnya, kemudian menjadi pusat kegiatan pendaratan dan pelelangan ikan yang berada di bawah Dinas Perikanan Pemda DKl Jakarta.

Pelabuhan Muara Angke dikendalikan oleh Badan Pengelola Otorita (BPO) Muara Angke, di mana dikembangkan menjadi pelabuhan ikan yang menampung semua kegiatan pendaratan ikan di Jakarta, sehingga semua pendaratan ikan secara perlahan-lahan dialihkan ke Muara Angke. Kegiatan yang akan diselenggarakan dilakukan untuk menampung semua hal yang 
berkaitan dengan perikanan, maka dibangunlah berbagai fasilitas pendukung guna kelayakan sebuah pelabuhan ikan. Status pelabuhan Muara Angke adalah pelabuhan ikan tradisional di Jakarta. Hal ini untuk membedakan dengan pelabuhan ikan modern seperti Muara Baru (http://www.jakarta.go.id/web/encycl opedia/detail/1955/muara-angke).

Alat tangkap yang ada di pelabuhan Muara Angke cukup terbilang bervariasi dan memiliki karakteristik berbeda-beda. Salah satu alat tangkap yang ada disana yaitu dari jenis jaring insang (gill net). Gill net yang digunakan nelayan Muara Angke masih sangat sederhana dan tradisional. Dari data statistik PPI Muara Angke tahun 2013 menunjukkan jumlah armada gill net yang mendaratkan ikan di Pelabuhan Muara Angke sebesar 118 unit yang berada pada urutan kelima terbanyak dari alat tangkap yang ada di Pelabuhan Muara Angke. Pentingnya melihat karakteristik alat tangkap gill net yaitu untuk pengelolaan dan pengembangan perikanan tangkap yang berkelanjutan kedepannya dengan mengamati kontruksi, manajemen operasi penangkapan dan keramah lingkungan dari alat tangkap gill net yang digunakan nelayan.

Oleh karena itu melalui penelitian ini nantinya dapat menggambarkan bagaimana keberlanjutan penangkapan gill net di pelabuhan Muara Angke kedepan. Dari uraian diatas penelitian ini bertujuan untuk mengidentifikasi karakteristik alat tangkap jaring insang (gill net) dan menguji ingkat keramahlingkungan alat tangkap jaring insang (gill net) di PPI Muara Angke.

\section{METODE PENELITIAN}

\section{WaktudanTempat}

Penelitianini dilaksanakan pada

bulan September sampaiOktober

2017 bertempat di PPI Muara Angke Jakarta Utara Provinsi DKI Jakarta (Gambar 1).

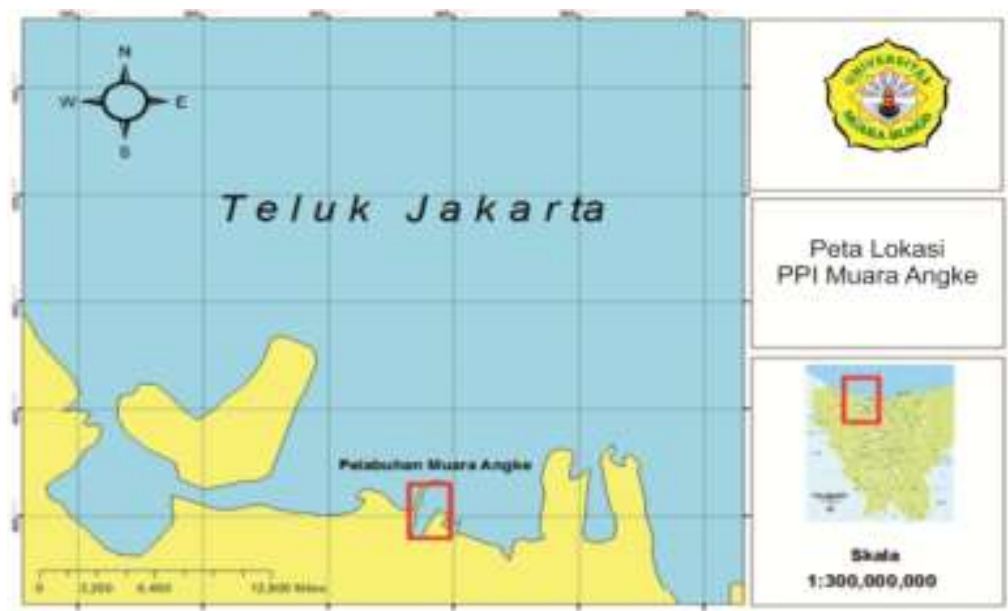

Gambar 1.PetalokasiPenelitian

\section{Sumber dan Teknik Pengumpulan} Data
Metode yang digunakan pada penelitian ini adalah metode survei dengan melakukan pengamatan dan 
observasi secara langsung ke lapangan dengan teknik wawancara terstruktur. Metode survei digunakan untuk memperoleh faktor dari gejalagejala yang ada dan mencari keterangan-keterangan secara aktual dari stakeholder terkait dalam menilai karakteristik alat tangkap dan keramah lingkungannya. Sumber data terdiri dari dua, yaitu data primer dan data sekunder.

\section{Bahan dan Alat}

Bahan sekaligus objek pada penelitian ini yaitu unit penangkapan gill net dan komposisi hasil tangkapannya. Sedangkan alat yang digunakan yaitu: alat tulis, kuisioner, jangka sorong, meteran, kamera digital dan alat pendukung lainnya.

\section{Analisis Data}

Data identifikasi karakteristik gill net dianalisis secara deskriptif dengan bantuan beberapa software seperti: Ms. Word, Ms. Excel, Corel Draw, Maxsurfdan Arcgis.Tingkat keramahan lingkungan alattangkap gill net di PPI Muara Angke dilihat dengan menggunakan 9 (sembilan) kriteria teknologi penangkapan ramah lingkungan berdasarkan ketentuan FAO (1995) yaitu :
1) Alat tangkap harus memiliki selektivitas yang tinggi.

\section{HASIL DAN PEMBAHASAN}

\section{Keadaan Perikanan Tangkap di PPI Muara Angke Jakarta}

Alat tangkap yang ada di Pangkalan Pendaratan Ikan Muara Angke Jakarta adalah Jaring cumi
2) Alat tangkap tidak merusak habitat dan tempat berkembang biak ikan.

3) Tidak membahayakan nelayan.

4) Menghasilkan ikan yang bermutu.

5) Produksi tidak membahayakan kesehatan konsumen.

6) Hasil tangkapan yang terbuang minimum.

7) Alat tangkap harus memberikan dampak minimum terhadap biodiversity.

8) Tidak menangkap jenis ikan yang dilindungi undang-undang atau terancam punah.

9) Dapat diterima secara sosial.

Analisis keramah lingkungan alat tangkap gill net dilakukan dengan bobot nilai terdendah 1 dan tertinggi 4. Klasifikasi tingkat keramah lingkungan dilakukan dengan melihat jumlah sampel $(\mathrm{N})$ maka indeks bobot nilai ditetapkan sebagai berikut :

1. $(10-17)=$ Sangat Tidak Ramah Lingkungan

2. $(18-26)=$ Tidak Ramah Lingkungan.

3. $(27-35)=$ Ramah Lingkungan

4. $(36-40)=$ Sangat Ramah Lingkungan $\cdots$

(bouke ami), purse seine, gill net, dan Bubu. Jumlah dan jenis alat tangkap di Pangkalan Pendaratan Ikan Muara Angke Jakarta dapat dilihat pada (Tabel 1).

Tabel 1. Jumlah dan jenis alat tangkap di Pangkalan Pendaratan Ikan Muara Angke Jakarta 


\begin{tabular}{lll}
\hline No. & Jenis Alat Tangkap Ikan & Jumlah (unit) \\
\hline 1 & Jaring Cumi (Bouke Ami) & 1919 \\
2 & Purse Seine & 387 \\
3 & Gill Net & 196 \\
4 & Bubu & 46 \\
\hline
\end{tabular}

Sumber: Pangkalan Pendaratan Ikan (PPI) Muara Angke (2015)

Berdasarkan (Tabel 1) alat tangkap Jaring Cumi (bouke ami) dan purse seine adalah alat tangkap yang paling banyak mendaratkan hasil tangkapannya di PPI Muara Angke Jakarta. Penggunaan alat tangkap jaring cumi (bouke ami) ini menggunakan kapal berukuran 2030 GT dan ada juga kapal di atas 30 GT. Lama operasi kapal Jaring Cumi (bouke ami) sekitar $40-60$ hari tergantung sehabisnya solar yang digunakan, sedangkan untuk kapal ukuran >30 GT pengoperasian lebih dari 60 hari. Alat tangkap lainnya seperti purse seinesebagian besar melaut selama 7-14 hari. Alat tangkap gill net dan bubu beroperasi selama 7 hari. Ikan hasil tangkapan jaring cumi (bouke ami) didaratkan di TPI Muara Angke dan untuk cumi-cumi sebagian besar langsung diangkut ke pabrik. Diantara alat tangkap yang ada di PPI MuaraAngke, alattangkap gill net mengalami peningkatan drastis 5 tahun terakhir, yaitu dari tahun 2011 sebanyak 39 unit menjadi 196 unit pada tahun 2015 (Gambar 2).

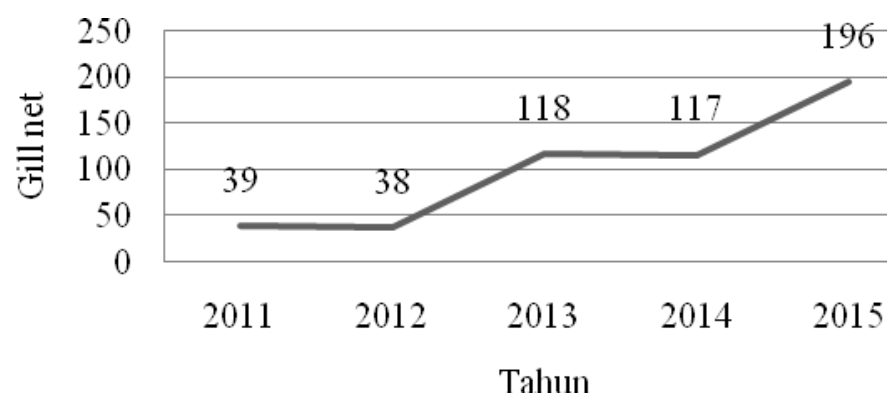

Gambar 2. Trend Jumlah Alatangkap Gill netyang Mendaratkan Ikan di PPI Muara Angke

\section{Karakteristik Jaring Insang (Gill net) di PPI Muara Angke}

\section{Nelayan}

Usia rata-rata nelayan gill net PPI Muara Angke yaitu 41,6 tahun, berarti nelayan PPI Muara Angke telah mencapai usia produktif dalam

\section{Armada Penangkapan}

bekerja. Usia termuda yaitu umur 26 tahun dan tertua 55 tahun. Nelayan gill net di PPI Muara Angke kebanyakan pendatang dari luar jakarta, berdasarkan hasil wawancara nelayan kebanyakan berasal dari Indramayu.

Ukuran armada gill net di PPI Muara Angke sangat bervariasi, berkisar antara 8 GT sampai 30 GT. 
Hasil wawancara menunjukkan bahwa ukuran kapal ini sangat tergantung pada modal usaha penangkapan ikan yang dimiliki nelayan. Armada yang digunakan nelayan PPI Muara Angke dapat dilihatpada (Gambar 3).

Gambar 3. Kontruksi dan Spesifikasi Kapal Gill net di PPI Muara Angke.

\section{Alat Tangkap Jaring Insang (Gill net)}

Model dan ukuran alat tangkap memiliki perbedaan disetiap wilayah operasi, menurut Andriyani et al, (2015) jaring insang (jaring sembilang) di Tanjung Balai Asahan memiliki ukuran panjang $10 \mathrm{~m}$, lebar 1,5 danmesh size 1,3 inci. Webbing jaring ini berbahan nylon dan berwarna hijau. Untuk ukuran kapal memiliki panjang $5 \mathrm{~m}$ dan lebar 1,5 $m$ denganberat 3 GT.

Hasil pengamatan alat tangkap gill net di PPI Muara Angke memiliki kesamaan seperti alat tangkap gill net pada umumnya, kontruksi (Gambar 4) pun tidak jauh
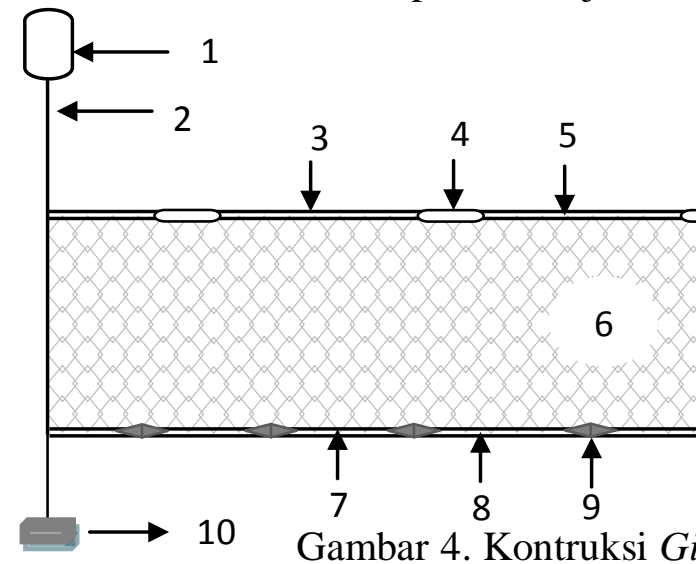

Keterangan:

1.Peluntang 2. Tali peluntang 3 . Tali pelampung

4.Pelampung5. Tali ris atas 6. Badan jaring

7. Tali ris bawah8. Tali pemberat 9. Pemberat

10.Pemberat batu

berbeda. Ciri khas gill net yang ada di PPI Muara Angke ini yaitu: pelampung pada badan jaring menggunakan pelampung mini purse seine dan target sasaran tangkapannya hampir semua jenis ikan (tidak mempunyai ikan target tangkapan yang spesifik).Padadesain (Gambar5) dapat dilihat bahwa jaring insang PPI Muara Angke memiliki ukuran mata jaring (mesh size) 50.8 $\mathrm{mm}$ atau 2 inci. Bahan utama badan jaringyaitu PA monofilament, dengan panjangjaring $1500 \mathrm{~m}$ dan memiliki kedalaman $15 \mathrm{~m}$. Tipe talinya yaitu $\mathrm{S}$ kearahkiri, dengan bahan PE dan PP 


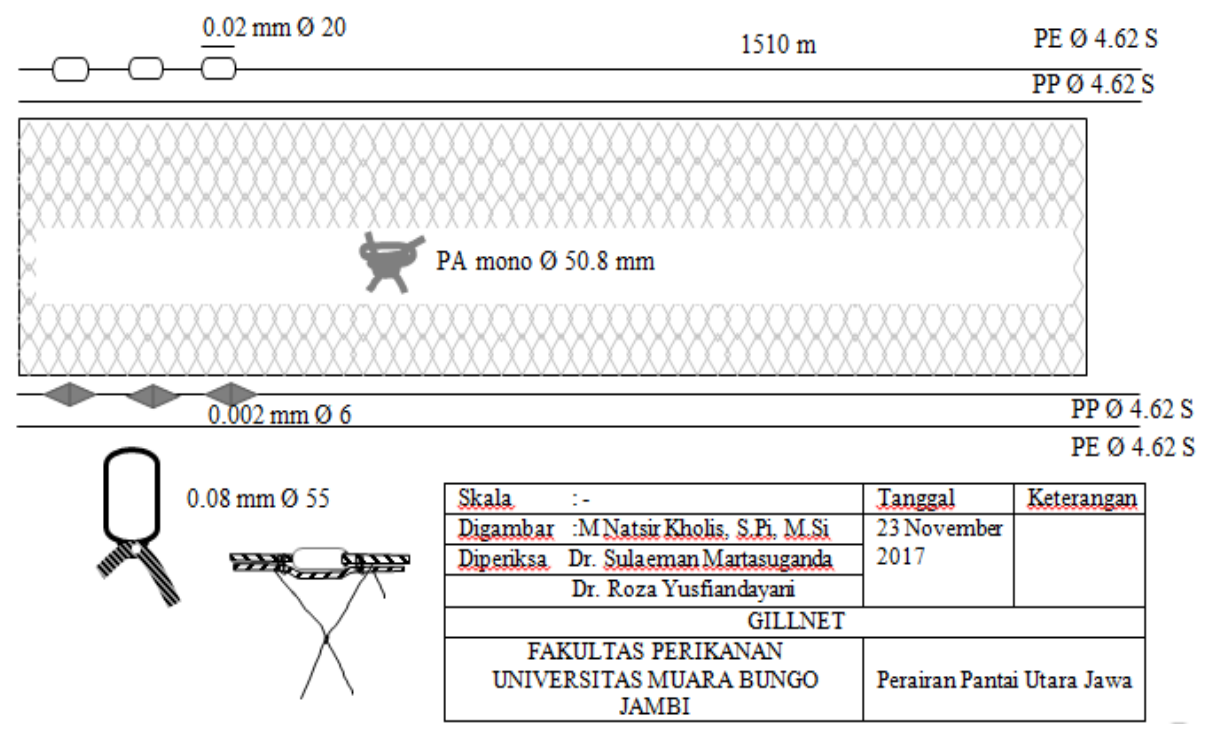

Gambar 5.DesainGill net di PPI MuaraAngke

\section{Daerah Penangkapan Gill} netNelayan PPI Muara Angke

Nelayan gill net Muara Angke melakukan operasi penangkapan ikan rata-rata tidak jauh dari wilayah pantai utara jakarta berkisar 12-200 mil laut. Fishing ground nelayan juga tergantung dari armada yang

\section{ManajemenOperasi}

PenangkapanIkanJaringInsang (Gill net) Nelayan PPI MuaraAngke

Penangkapan ikan sangat memerlukan manajemen usaha digunakan, nelayan yang memiliki armada ukuran GT lebih besar otomatis jangkauannya lebih luas. Nelayan gill net di PPI Muara Angke memiliki beberapa fishing ground seperti: LautJawa, Laut Karawang, Kep.Seribu, dan Pantaiutara Jakarta.

dalam melakukan operasi penangkapan ikan di laut. Salah satunya menentukan keuntungan dan kerugian yang didapat dari hasil tangkapan ikan yang didapatkan, agar mampu melakukan penangkapan secara berkelanjutan.

Tabel 2. Estimasi Manajemen Penangkapan Gill netNelayan PPI MuaraAngke

\begin{tabular}{|c|c|c|c|c|c|c|}
\hline \multirow{2}{*}{$\begin{array}{c}\text { Ukuran } \\
\text { Kapal } \\
\text { (GT) }\end{array}$} & \multirow{2}{*}{$\begin{array}{l}\text { Pengeluaran } \\
\text { per Bulan } \\
\text { (Rp) }\end{array}$} & \multirow[b]{2}{*}{$\begin{array}{c}\text { Daerah } \\
\text { penangkapan }\end{array}$} & \multirow[b]{2}{*}{$\begin{array}{l}\text { Lama } \\
\text { operas } \\
\mathrm{i} / \text { trip } \\
\end{array}$} & \multirow[b]{2}{*}{$\begin{array}{c}\text { Total } \\
\text { Tangkapan } \\
(\mathrm{Kg}) \\
\end{array}$} & \multicolumn{2}{|c|}{ Hasil Tangkapan } \\
\hline & & & & & $\begin{array}{l}\text { Kondisi } \\
\text { Ikan }\end{array}$ & Tempat Pemasaran \\
\hline 25 & 3.500 .000 & Laut Jawa & 30 & 11.505 & $\begin{array}{l}\text { Ada yang } \\
\text { segar } \\
\text { ada yang } \\
\text { rusak }\end{array}$ & $\begin{array}{l}\text { PelabuhandanIndust } \\
\text { ri }\end{array}$ \\
\hline 26 & 2.500 .000 & Laut Karawang & 15 & 300 & $\begin{array}{l}\text { Kondisi } \\
\text { bagus }\end{array}$ & $\begin{array}{l}\text { PelabuhandanIndus } \\
\text { tri }\end{array}$ \\
\hline 30 & 2.000 .000 & $\begin{array}{l}\text { Kep. Seribu } \\
\text { Pantai Utara }\end{array}$ & 40 & 8.500 & Segar & Pelabuhan \\
\hline 25 & 1.500 .000 & Jakarta & 30 & 10.200 & Segar & Pelabuhan \\
\hline
\end{tabular}




$8<1.000 .000 \quad$ PantaiUtara jakarta $1-2 \quad 100-600 \quad \begin{gathered}\text { Kondisi } \\ \text { bagus }\end{gathered}$ Pelabuhan

\section{Jumlah Hasil Tangkapan}

Jumlah hasil tangkapan nelayan gill net berdasarkan hasil wawancara yang terbanyak didominasi oleh tongkol dan tenggiri.

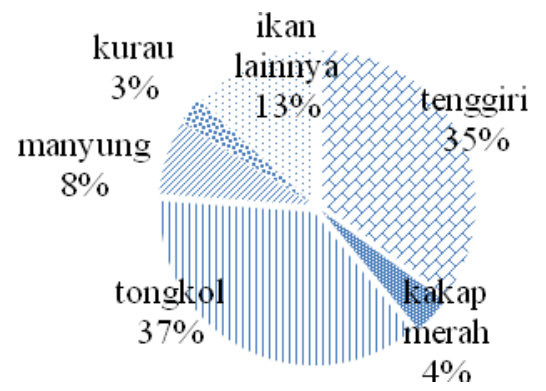

Ikan yang dianggap by catch yaitu ikan yang tidak memiliki harga jual seperti: kepiting batu. Proporsi hasil tangkapan gill net dapat dilihat pada (Gambar 6).

Gambar 6. Estimasi Proporsi Jumlah Hasil Tangkapan Gill net di PPI Muara Angke per-Trip

\section{Estimasi Harga Ikan dan Kualitas Ikan Hasil Tangkapan}

Harga suatu species ikan pada umumnya dapat berbeda-beda tergantung musimnya. Ikan-ikan yang ditangkap oleh nelayan gill netdi PPI Muara Angke rata-rata memiliki nilai ekonomis penting. Harga yang tertinggi berdasarkan hasil wawancara dengan nelayan yaitu ikan kurau, diikuti tenggiri dan kakap merah.

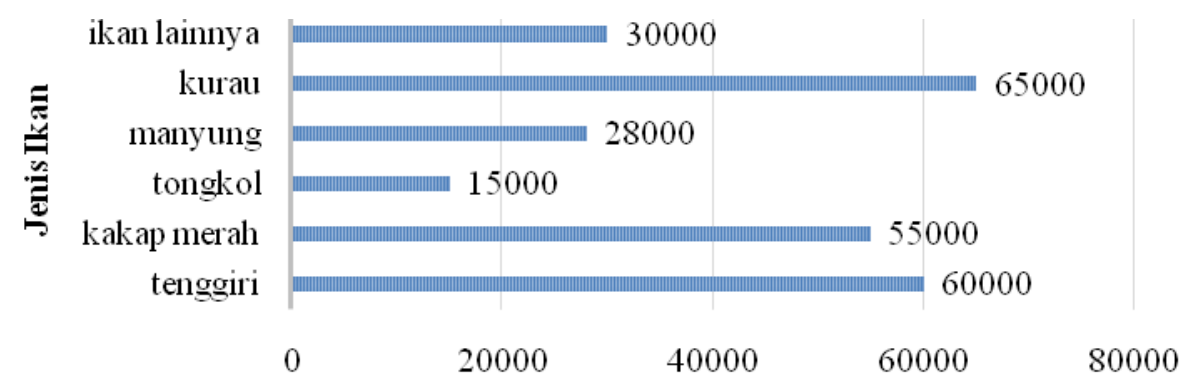

Kisaran Harga Ikan

Gambar 7. Kisaran Harga Hasil Tangkapan NelayanGill net diPPI Muara Angke

Kondisi ikan hasil tangkapan nelayan gill net yang didaratkan di PPI Muara angke rata-rata memiliki kondisi yang baik dan segar, tetapi ada juga beberapa ikan yang mengalami kerusakan. Ikan-ikan yang mengalami kerusakan kemungkinan karena benturan pada dinding palkah ataupun akibat gesekkan jaring. Hasil tangkapan tersebut dipisahkan berdasarkan ukuran dan jenis ikan agar mempermudah proses pelelangan dan penjualan. Berdasarkan hasil pengamatan proporsi ikan segar, tidak segar dan rusakdapat dilihat pada (Gambar 8) dibawah ini: 


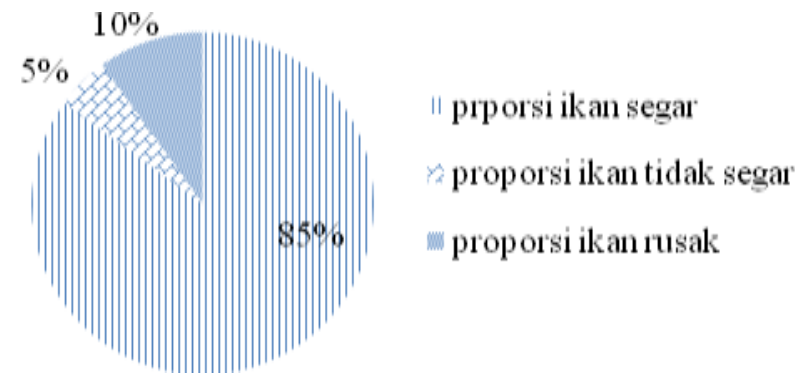

Gambar 8. Proporsi Kualitas Hasil Tangkapan NelayanGill net di PPI Muara Angke

\section{Penilaian Keramah Lingkungan Alat Tangkap Gill Net di PPI Muara Angke}

Tingkat keramah lingkungan alattangkapgill net di PPI Muara Angke dianalisis menggunakan kriteria FAO (1995). Kesuksesan analisis ini tergantung tanggapan responden terhadap apa yang kita tanyakan pada mereka. Hasil wawancara menunjukkan alat tangkap gill net di PPI Muara Angke dengan skor nilai 30,5termasuk kedalam alat tangkap yang ramah lingkungan. Menurut Sumardi, et al. (2014) alat tangkapgill net di perairan kota Banda Aceh adalah alat tangkap yang memiliki tingkat keramahan lingkungan paling tinggi dan mempunyai selektifitas yang tinggi dibanding alat tangkap lainnya yang ada di Banda Aceh. Latuconsina, (2010) juga menyatakan jaring insang permukaan tegolong ramah lingkungan dengan memenuhi 7 dari 8 indikator ramah lingkungan, yaitu tidak diizinkan menangkap di kawasan konservasi.

Berdasarkan (Gambar 9) menunjukkan bahwa alat tangkap gill net di Muara Angke belum memiliki selektivitas tinggi karena masih berada pada zona merah (Sangat
Tidak Ramah Lingkungan), hal ini dikarenakan alattangkap gill net ini menangkap lebih dari lima jen isspecies ikan. Hal ini tidak jauh beda dengan alat tangkap gill netdi Banda Aceh dengan persentase 3,5\% nelayan menyatakan mampu menangkap lebih dari tiga jenis species sekali hauling, $82,5 \%$ nelayan menyatakan mampu menangkap kurang dari tiga spesies dengan ukuran yang kurang lebih sama dalam sekali hauling, dan1,8\% nelayan menyatakan mampu menangkap paling banyak tiga spesies dengan ukuran yang berbeda jauh dalam sekali hauling (Sumardiet al, 2014). Enam kriteria lainnya sudah dapat dikatakan sangat baik (Sangat Ramah Lingkungan) dengan zona hijau. Dua kriteria berada pada zona biru (Ramah Lingkungan). Menurut Rianasari (2018) alat tangkap di Kecamatan Kuok Kabupaten Kampar Provinsi Riau yang memiliki tingkat keramah linkungan kategori sangat ramah lingkungan adalah pengilar, bubu, pancing vertikal, giilnet, bububotol bekas, dan pancing, sedangkan alat tangkap tangkul, serok besar, jaring lingkar, jala, dan senapan adalah alat tangkap yang ramah lingkungan. 


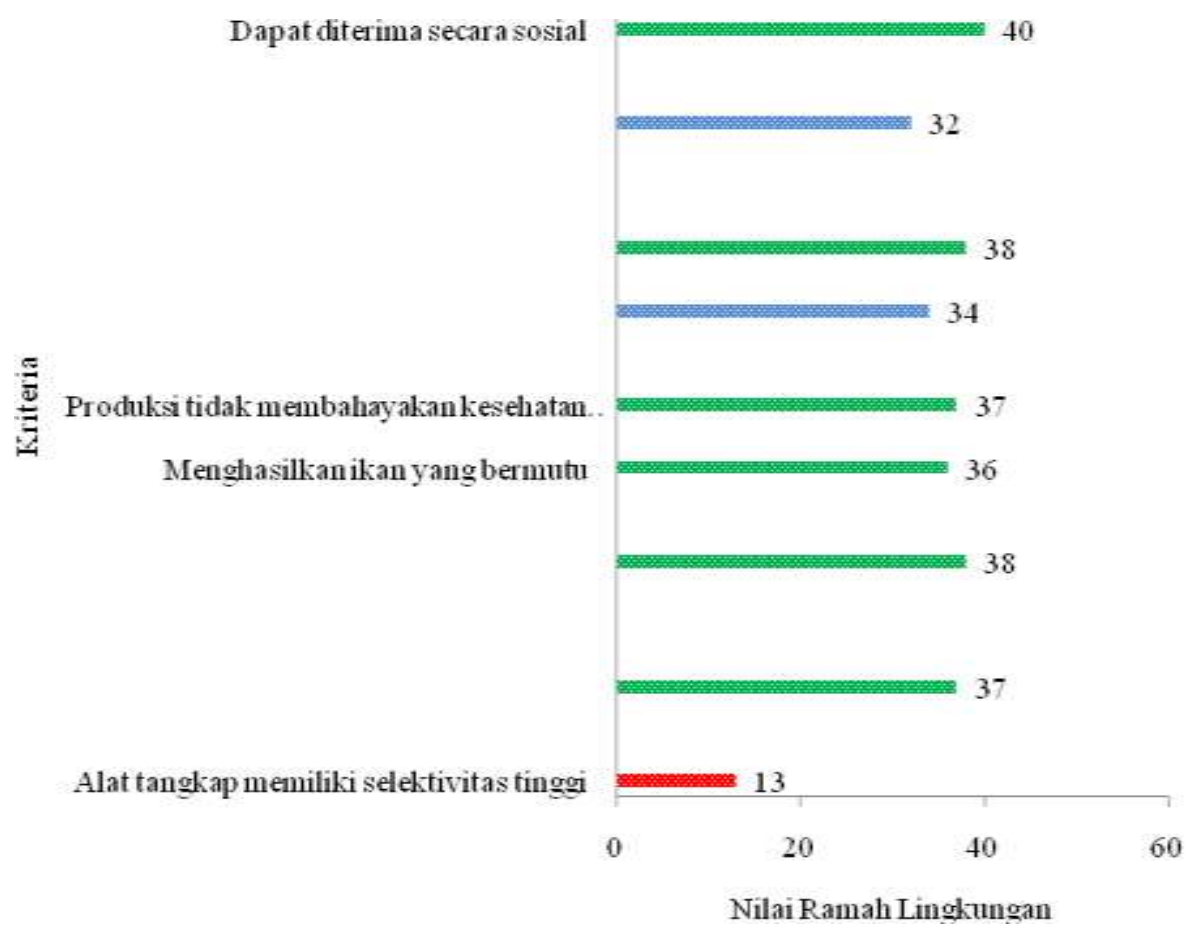

Gambar 9.GrafikKategoriHasilPenilaian

Tingkat

Ramah LingkunganAntarKriteria

Menurut Dahuri (2016) untuk menuju Indonesia sebagai poros maritim dunia maka diperlukan teknologi yang tepat untuk meningkatkan produktivitas, efisiensi, daya saing, ramah lingkungan dan keberlanjutan (sustainability). Alat tangka pgill net di PPI Muara Angke sudah mengarah kearah keberlanjutan,. Hal ini sama dengan pendapat Kholis (2018); Nurani (2002) bahwa teknologi

\section{KESIMPULAN DAN SARAN}

\section{Kesimpulan}

Hasil dari penelitian ini dapat disimpul kan bahwa karakteristik alat tangkap jaring insang (gill net) di PPI Muara Angke yaitu: webbing memiliki mesh size 2 inci, webbing menggunakan pelampung mini purse seine, tidak memiliki ikan target tangkapan yang penangkapan ikan yang unggul memiliki kriteria: bila ditinjau dari aspek biologi penangkapan yang akan dikembangkan tidak merusak atau menggangu kelestarian sumberdaya, secara aspek teknis efektif digunakan, dari aspek sosial dapat diterima oleh masyarakat nelayan dan secara ekonomi teknologi tersebut bersifat menguntungkan. spesifik, nelayan gill netrata-rata telah mencapai usia produktif dalam bekerja, kapal yang digunakan berkisar 8-30 GTdan kualitas hasil tangkapan rata-rata dalam kondisi segar. Hasil analisis alat tangkap ramah lingkungan gill netdi PPI Muara Angke dapat dikategorikan alat tangkap yang ramah lingkungan dengan skor 30,5 . 
Saran

Sebagai saran pada penelitian ini diharapkan dilakukan penelitian

\section{DAFTAR PUSTAKA}

[BPS] BadanPusatStatistik. 2013. LaporanTahunan BPS Kota Jakarta Utara, DKI JakartadalamAngka (ID).

[BSPP].BadanStatistikPelabuhanPeri kanan. 2015. LaporanTahunan BSPP

PangkalanPendaratanIkanMuar aAngke, Jakarta Utara, DKI Jakarta (ID).

[FAO] Food and Agricultural Organization. 1995. Code of Conduct for Responsible Fisheries.Rome (IT). 41 pp.

[UPT].Unit PelaksanaTugas PKPP PangkalanPendaratanIkanMuar aAngke.2011. Laporan UPT PKPP

PangkalanPendaratanIkanMuar aAngke, Jakarta Utara, DKI Jakarta (ID).

Andriyani, H., Brown, A., \&Rengi, P. 2015.

StudiTeknologiAlatTangkapJar ingSembilang yang MenggunakanTuasan di DesaPematangSeiBaruKecama tanTanjungBalaiAsahanKabup atenAsahanProvinsi Sumatera Utara.JurnalPerikanandanKela utan. 20 (1): 32-40.

Dahuri R. 2016. Мепији Indonesia SebagaiPorosMaritimDunia.

Bogor (ID): RodaBahari Press. 294 hlm.

Http://www.jakarta.go.id/web/encycl opedia/detail/1955/muaraangke [diunduh, 7 Januari 2019].

Kholis, M.N., Wahju, R.I., \&Mustaruddin. 2018. lanjutan yang lebih intensif untuk pengembangan usaha penangkapan gill net di PPI MuaraAngke.

KeragaanAspekTeknis Unit TeknologiPenangkapanIkanKu rau di PambangPesisirKabupatenBen gkalisProvinsi Riau. JurnalTeknologiPerikanandan Kelautan. 8(1): 67-73.

Latuconsina, H. 2010. Identifikasi Alat Penangkapan Ikan Ramah Lingkungan di Kawasan Konservasi Laut Pulau Pombo Provinsi Maluku.Jurnal Ilmiah Agribisnis dan Perikanan. 3 (2): 23-30.

Nurani TW. 2002. Aspek Teknis dan Ekonomi Pemanfaatan Lobster di Pangandaran Jawa Barat. Bul PSP, 9 (2): 29- 46.

Rianasari, A., Bustari, Usman. 2018. Identifikasi Alat Tangkap Ramah Lingkungan yang Beroperasi Disepanjang Perairan Sungai Kampar Kecamatan Kuok Kabupaten Kampar.JurnalOnlineMahasis wa. Universitas Riau, 13hal.

Sumardi, Z., Sarong, MA., Nasir, M. 2014. Alat Penangkapan Ikan yang Ramah Lingkungan Berbasis Code of Conduct For Responsible Fisheries di Kota Banda Aceh..Agrisep. 15 (2): 10-18. 